\title{
Science in Social Practice ${ }^{*}$
}

\author{
George Herbert MeAd \\ University of Chicago \\ Social Thought \& Research, 2000, Vol. 23, 1\&2 \\ Introductory Notes
}

This paper represents the text for the Annual Phi Beta Kappa address given at the University of Kansas on Friday evening, March 3, 1911, under the announced title of "Science in Social Practice." The University Daily Kansan, Thursday, February 23, 1911 (Vol. VII, No. 58, p. 1), carried the following story announcing Mead's visit:

Phi Beta Kappa Speaker. Professor George B. Mead, of the philosophy department of Chicago University, will deliver the annual Phi Beta Kappa address on Friday evening, March 3. Mr. Mead is an excellent talker and comes with a national reputation as a speaker. The speech will be open to the public and all members of the university are invited.

The Daily Kansan also carried a story reporting on Mead's talk on Saturday, March 4, 1911 (Vol. VII, No. 61, p. 1):

PLEA FOR SOCIAL SCIENCE: Professor Meade Addresses Phi Beta Kappa in Chapel, Professor Geo. B. Meade, of the department of philosophy at the University of Chicago, gave the annual Phi Beta Kappa address last evening in which he made a strong plea for scientific methods in social practices. He explained that while physical science has made vast strides, social science has had very little advancement since the time of the ancients. The definition of an atom has changed twenty

* Harold Orbach of the Department of Sociology at Kansas State University has kindly provided us with this previously unpublished manuscript from his Mead archive and also wrote the introductory notes. We are deeply indebted to Orbach not only for contributing this article but also for submitting to a day-long interview with the editors. 
times to meet new phenomena, while the minutely worded laws which control justice in this country, have not been modified for centuries.

According to Professor Meade, in criminal actions science should be used in dealing with each problem as it comes up and motives, not facts, should be the ruling factors. Some of the steps which have been taken to put science in social practice are the recall and referendum, the juvenile court and the parole system. Professor Meade maintains that justice should be the socializing of an individual rather than punishment. He closed the remarks by saying: "Nothing could please me more than to see science have the same right of way in social practice as it has in physical practice."

If the story in the University Kansan is accurate, Mead added this final sentence extemporaneously at the end of his written text.

\section{Science in Social Practice}

There is no more striking difference between the ancient and the modern worlds than that revealed in their fashions of dress, of armor, and of building. Study the garb of men and women of Greece and Rome, of Persia, and of Egypt during the thousand years and more that are covered by the remains of their monuments, and then place beside these fashions, unchanged in their essentials during the whole period, the bewildering variety of dress which confronts one who turns to the repositories of medieval history, culture and custom. From the early centuries in which the modern world commenced to emerge from the old, uneasy change has characterized the fashion in which men and women have clothed themselves at home, at court, and in the field.

The same stability of equipment marks the method in which armies were fitted for fighting by the nations and civilizations of the ancient world. The masses of ancient troops which conquered the world for Persia, the phalanxes which disputed the hegemony of Greece, the legions of Rome which presented the ultimate arm of ancient warfare, remained in their essentials unchanged throughout the histories of the empires which phalanx trampled down and scattered the masses of Persian troops and stood in their places until the short swords and flexible maniples of the Roman legions disintegrated them in turn and superseded them as the final victorious formation.

The same uniformity characterized the arms of offence and defence. They were perfected and fashioned of superior materials. They were superseded by the arms of other nations and other civilizations, but in their form and nature, while they were in fighting hands, they remained unmodified by theory or practice.

Turn to the treasures of our museums and follow the series of vases and vessels and mirrors, the pins and brooches, and see how persistent the types of articles were, how the great forms of ancient art and manufacture dominate the usage of centuries and more than centuries. See the ideas of Greek society embodied in the series of representations of Greek divinities. Study the growth in perfection, the increasing intellectual content in the same form, and still the steady reforming and restating of the same figure and the same meaning in a Zeus or a Pallas Athena.

Turn to the house and note the same form in the structure of the home of the citizen and in the house of the god. The temple is wonderful in the perfection of its lines and the balance of its proportions, but it is the perfected home of the city's greatest citizen. The palace of the Roman emperor but multiplies the house. The unit is the same and the form of the unit unchanged as were the ideas in Plato's World beyond the Heavens.

The forms of thing remained. The Aristotelian essences which are Platonic ideas embodied in individual things represent in their finality the fashion that was slowly brought to perfection by art and 
artisanship, to self-consciousness by philosophy, but which existed us sub specie aeternitatis; not as the fashion of our world which passes away.

It is quite in accordance with this attitude of the ancient world that practice remained largely unaffected by physical theory. It would be difficult to point to any phase of practice in war, in the arts and manufacture, in engineering or agriculture in which the practice of the ancients was transformed by their science. Archimedes created the science of Statics, but it was as a field within which to carry further the mathematics of his time and that mathematics was geometry. Physical science in Greece reached its climax in cosmology, its statement of the movements of the heavenly bodies, and the final statement made by Ptolemy met the demands of the observations of the times. Its distinction between the heavenly spheres and the sublunar sphere, its distinction between the soli earth with its quality of weight and the substances of water, air, fire, and ether, satisfied the problems which suggested themselves to the physicists. Medicine advanced in its surgery and the consequent study of anatomy to considerable results of the scientific character. But the therapeutic treatment of disease never rose above an empirical practice that was largely controlled by tradition and was too confined by ignorance of physiology and the chemistry of its materia medica to become scientific.

Even when geometry had acquainted educated men with the theory of measurement of surfaces and solids we find that in Egypt, where was the center of ancient science, surveying for the government of the Ptolemy's clung to ancient rules of thumb which were palpably incorrect. Apart from the mythical tales of the achievements of Archimedes in the defence of Syracuse there is no evidence that ancient physics modified in any material degree their practice in war. Their architecture presented no problems that aroused men to consider the nature of physical forces. Their whole conduct lay so completely within the traditional practice that men felt no inclination to invention. Indeed throughout the entire history of the ancient world it would be impossible to point to $t$ a single invention which had reconstructed any form of physical practice. Advance consisted in the realization of the ideas that lay behind the traditional methods and customs and operations, and their perfection, and even this perfection was conceived of largely from the standpoint of the aesthetic judgement.

If we turn now to the beginnings of the modern world we find in the most universal and essential fields of physical practice, problems which inevitably forced upon the consciousness of Europe the study of subjects which were without interest for the ancients or were even beyond their ken. Note the rapid changes which took place in warfare. See the development of the defensive armor of the knight and his castle pushed to such extremes that new forms of tactics and new forms of weapons of offence were invented to overthrow the iron encased cavalry and their impregnable castles. The light armored bowman unhorsed the knight, the demand for an adequate weapon with which to attack the castle led to the invention of gunpowder and the cannon, and the whole field of warfare became the field of physical problems, that invited the study of the physicist, and forced dynamics upon the consciousness of the fourteenth century mathematicians of Italy. The restless change in the manners of fighting carried with it an inevitable curiosity as to the power which new weapons promised. It carried with it the question whether the offence would be equal to the defence, and these were problems that could not be stated except in terms of dynamics.

The ancient temple, being but the idealization of the ancient house carried no other problems with it than those of bringing the building materials to the positions which a simple architecture demanded. The achievement of the Parthenon was the glory of the artist not an engineer. If the stone could be brought and placed in its proper course there was no need to question whether it would crush its foundations. The sides of the temples of the noblest dimensions never reached a height in comparison with its width which raised doubts as to it toppling over with the weight it bore. There were no problems of the 
side thrust which awakened the anxiety of medieval architects and led to the buttressing of the walls of medieval cathedrals.

The cathedral was not the house of the divinity who was also a citizen of the city. It was the house of the God of otherworldliness. It strove to overpower by its contrast with the mean dimensions of the houses of the city. Its nave, narrow in proportion to its height, gave that sense of upward striving which should carry religious devotion away from the city which the Grecian temple idealized. Its enormous and towering spires directed attention to heaven. Its walls shut in from the world its worshippers by impressive masses. Every motive in its structure set itself in opposition to the daily life and practice of the inhabitants of the medieval city. Thus while the building of the Greek temple carried with it no physical problems that were not involved in the building of the house of the ordinary citizen, the cathedral by the very infinity it sought to symbolize brought with it problems of stresses and strains, of the crushing weight of piled up walls and towers, which could be solved only by a science which recognized that the stones in place were still forces which must be conceived of as in motion.

Literature in Greece and Rome was for a literary class and the copyist was equal to the task of its dissemination. Where the drama or the epic poem or the historic tale or pamphlet sought a wider audience, the theater or the concourse at the Games provided the audience; and information, and opinion, and emotional appreciation, attended upon the art of the reader, the rhapsodist, and the actor. Greek and Roman religions were religions of cults and custom and not of monuments and books. Medieval heresies were changing fashions in religion and demanded that the divine oracles should be at the disposal of every troubled mind, and out of this demand arose the art of printing.

I have said enough to indicate, and I can do no more tonight, that out of the restless changing practice of the modern world sprang the modern theory that sought to solve the problems which this changing practice brought with it. I have suggested this, because I wish to call your attention to the manner in which modern science has solved these problems. I think that the method which has been successful in conquering the obstacles which physical practice has faced, may well be employed in dealing with the difficulties with which social practice is confronted.

I will state by way of preface just what I take physical practice to be. It is first of all approach toward or flight from objects which are distinguished directly by the eye or other distance sense, or are presented by the eye or other distance sense, or are presented by imagination or though, upon some implication, that carries the mind beyond the field of vision. In the second place it is a coming to close quarters with the objects toward which man has moved, a manipulation covers all animal practice. It is specialized in the pursuit and flight of the beast of prey and his victim processes of reproduction, in the parental care and dependence of infant forms; and in man this behavior is only complicated, raised to a higher power, by the development of manipulation.

Man is the animal with hands that finds or makes and uses tools. The processes of manipulation concentrate many acts into one. Every act is at bottom but approach and manipulation, but this manipulation may result in covering indefinite distances, and give us a capacity which raises the force of a man's hand to the nth power. When we travel with the locomotive, the steamship, or the aeroplane, and talk with the telephone and the telegraph, and crush with the hydraulic hammer, and transport overwhelming weights with electric cranes, we have but complicated the simple processes of approach and manipulation by the structure of tools, and these tools have arisen through manipulation. Man increases the diameter of his habitat by the radius of the tool he uses, or he may contract and reduce that diameter to the realm of a molecule, and be king of the infinite space within the domain of a nutshell. Thus tools either contract or expand distances or multiply or refine the power of the human hand. 
If we glance again at the history of the ancient civilizations we see that the tools which man used during these centuries were hardly different in principle from those which primitive man used since he first hurled the missile, pried with a lever, crushed with a club, and spit with a sharp stone, dissipated matter with fire and changed its inner nature by cooking, subdued the wild animal to carry and pull, and served himself upon the water with the sustaining buoyancy of wood. Ancient mechanism departed from these types in surprisingly few instances. That their tools of industry and war were more refined and of better stuff, and conquered wider horizons and added more power to the arm and more nicety to the touch than the tools of the savage is not in question, nor that with typical tools of early man these societies accomplished marvels by the organization of men in groups and the selection of high capacities in their artisans and artists. Social organization raised the tools with which the ancients worked to a vastly higher power, but the nature of the tools set definite limits beyond which ancient society could not go. With few exceptions the ancients merely modified and perfected tools, the prototypes of which were to be found in the hands of the savage Teuton in the forests of Germany. Ancient technology like the descriptive science of the ancients, defined and perfected its objectsit did not create them.

The problems of warfare, of building, of the multiplication of books, led to the invention of weapons and forms of forts and bastions, and finally to gunpowder with all the revolution that has followed in its house, was not a temple, that was typical of all that other human structures were not,- the cathedral, to the printing press, to the book. It led to the telescope and the microscope, to the compass, to the pendulum, to the clock that was a function of the pendulum, and to the scientific apparatus which has arisen out of the problems of which a modern science has grown constantly more conscious. These were all of them new objects, novel things that had not existed before even in prototype, if we examine their nature. But while the appearance of such new tools with which the medieval world with slowly increasing velocity reconstructed the world in which it lived, built even a new physical universe, and laid the foundations for a new type of industrial democracy the like of which had not been found among the city states of the old world, while these new tools and the achievements they made possible are startling and absorbing to those who can read history aright, there lies back of them and is to be found instinct within them a new method which is even more important, and even more startling, when we are able to grasp its import.

It is more important because it is the method by which science in the physical world is constantly constructing new tools and new object that did not exist before. This new method which makes the greatest difference between the consciousness of the old world and the new, is that which gets its first recognized expression in the scientific work of Galileo. It appears here as dynamics, a new science which enters fields closed to Archimedes, and its characteristic is that it starts with a law of change as its fundamental reality and defines its objects in terms of the uniformities in these changes. The Analysis of Descartes and the Calculus of Leibnitz and the Fluxions of Newton wee developments of this new method in dealing with physical objects. Its permanent elements were by finding a system within which these changes take place, as Newton finally did, it became possible to define physical things in terms of the changes which arose within the system, until now the ultimate terms in which our physical science defines all its objects are velocities and changes in velocity. The biologic sciences waited long before the doctrine of evolution stated the animals and plants in terms of change. Darwin at last could formulate a hypothesis which showed how the species of animals and plants could have arisen out of the living processes. The animal became a product of the biologic changes which we call life. We define the animal or plant in terms of the live processes. We do not conceive of life as a quality with which animals and plants are endowed.

To repeat: the modern in its restlessness has adopted a new point of view. Change has become the fundamental fact. The only permanencies are ways in which changes take place. This not only gives us new terms in which to describe the world but it makes 
incumbent upon science that it should constructs its objects out of these elements, these velocities and changes in velocity. Where the Aristotelian scientist but described what his perception presented to his mind, while he but abstracted the essential qualities from this perceived object and gathered these together as the nature of the object, the modern scientist describes his object as of such a nature that it never could be perceived. Molecules and their constituent atoms would defy any conceivable perception. Molecules and atoms are but conceptual objects which enable us to state the laws of change within which the physical object must be constructed, and for that reason they are quite independent of the meaning and value which human experience gives to them at any one time. The molecular structure of matter is indifferent to the character of the living organism in which we conceive it to appear. It is just as indifferent to the passing inanimate textures through which we conceive it to have passed form the primordial stardust out of which solar systems have arisen. For science an object is not what we perceive it to be, but a series of processes by which we account for our perceived world coming into being. The fact that Aristotelian science accepted the world of perceptual experience as the essence of objects, as the reality of things, fixed the objects of human experience in the form which this science found them.

There are, then, two striking characteristics of the modern scientific object. First that it is constructed out of changes whose laws are known or to be known, and therefore subject to a high degree of control, for a change whose law is known can be used, can be employed, can become a tool. The second characteristic is that the structure of the scientific object is itself quite indifferent to the values and meanings which our experience endows it with. It is therefore material out of which new objects of experience can be constructed. From it can be made the tools by means of which the world can be made anew. In a word, physical science does not recognize any metaphysical nature in the world of physical practice. It presents hypothetical structures such a molecules, vortex atoms, ions and electrons, which enable it to state the laws of the changes that incessantly go on about us; and by those laws we are able to control this world, by the structure of new tools or what is the same thing, new physical objects.

It is on this account that physical practice has been revolutionized within two centuries. The laboratories of modern physical science are workshops in which to construct the tools which will make us equal to the tasks which our practice presents to us. It is because we can look upon life and death as the same in the view of physical science that we have been able to accomplish so much for the conservation of life. It is because for the laboratory the process of disease and health are alike that we can make health to abound where sickness was dominant. It is because science has been able to abstract from the metaphysical essences of things that invention has been able to conceive of the new tools which have brought million into close relations who would otherwise been ignorant of each other's existence.

The scientific hypothesis is a construct which goes beneath the former import of things. It knows only one test, that of experiment. If this is satisfied, the scientist or inventor may state matter in any form that his hypothesis demands. It recognizes only the problem which arises in practice, the conditions which the solution of the problem set, the hypothetical object, and the final test of trial. Thus science has conceived of electricity as a fluid and again as a vibration, and now it conceives of ions and electrons, subatomic elements of electricity. The former physical atom, the supposedly irreducible minimum of matter, has been shattered into a thousand particles because the study of electrolysis, $\mathrm{x}$-rays, and radioactivity are most conveniently stated in terms of these fragments of that which physics had before defined as the ultimate particle. At no barrier can the metaphysician stand and say "thus far and no farther." There is no ultimate being guaranteed by philosophic doctrine that may not be resolved by the scientific imagination, if only the scientist will make of his new conceptual object a better medium for the construction of the tools of thought and practice. 
Who will attempt to say what hypotheses will govern the thought of our grandchildren? How shall we conceive of the strange phenomena of disease following upon the activity of micro-organisms in the human system, or the still stranger phenomena of immunity to their attacks? A brilliant German scientist imagines these micro-organisms set with protuberances and hooks with which corresponding excrescences upon the particles of chemical substances introduced into the blood interlock. He finds this the easiest method of conceiving the results he reaches, and who will say him nay. Perhaps another decade will find these excrescences securely lodged in the textbooks of organic chemistry. Whatever image will best enable man to gain readiest control over the disease and achieve the immunity is welcome. Whether the conception is fantastic or is at variance with former doctrine are questions that will never be asked. With such complete freedom does the physical scientist enter upon his task of making our world more comprehensible and our practice, therefore, more successful.

What is the situation in social practice? Is the same freedom allowed to science in controlling the social conduct? From one point of view this question seems ill advised, and that is the standpoint of science itself. How can we demand freedom for science in the construction of social objects in testing new social hypotheses, when social science has not as yet become exact? Until we have isolated the uniformities of social change and can show acknowledged laws of social processes, it would seem idle to seek for greater freedom for the scientist; to encourage him to form and test hypotheses when he is unable to define these in terms of fixed ratios of social movement. To make the question more concrete, can we establish a science of Eugenics when we do not understand the changes which are responsible for variation of children from the parent stocks, when were are still unable to present a theory of heredity which can be brought to the final test of experiment? Have statistics revealed to us laws of social change which can lay claim to the exactness of the laws of the physical sciences? Social scientists have for example studied suicide, birth rates, and pauperism in the light of changing social conditions, but while they recognize that uniformities are there they can not so isolate them that they can use them as the physical scientist employs his laws of motion. They conditions which affect these phenomena are so terribly intricate and so far beyond the reach of laboratory control that the prospect of an exact social science sees as far from realization at the meeting of parallel lines at infinity. Shall we say then that social science must remain in the metaphysical period, that we must satisfy ourselves with the definition of men and women and children as these are given to us in our books of statutes, in our political handbooks, and in the doctrinal theology, because we cannot state in terms of exact laws the social processes out of which arise personalities, characters, good and evil, standards of conduct or the content of social justice?

It is certainly true that our social objects are still largely metaphysical. To begin with, while the psychologist in his experimental science has abandoned the soul and substituted for this entity the self, and while he is somewhat tardily studying the processes by which this self arises in consciousness, our education still conceives the mind as a container into which information is to be poured, into whose fibre the associations of ideas are to be drilled. We talk vaguely of the education of the child being the life of the soul, but our practice belies our talk. It is the child's soul which is instructed. School life is not the development of the child's self. In fact the pedagogue has carried over something of the metaphysical nature of the soul into the brain, and conceives of images as stored up in brain cells and rules of arithmetic and speech drilled into brain fibre. Our psychology ha sin no small degree separated the brain, or let us say the central nervous system, from the rest of the organism and given it as a sensorium something of the metaphysical character of the soul. It would be easy to extend this criticism to other phases of our school room psychology. I know of nothing that interfered more with a healthful application of the psychology of attention than the attitude which our school discipline takes toward the wandering of attention. We are back here in the metaphysical dogma of an indifferent will. The child can attend if he will. 
But let us change the field of illustration to hat of politics and see how completely our practice and our would be scientific theory are at odds with each other. Social theory recognizes that the political self arises out of social control. Whether we conceive of this in terms of imitation or of social instincts or both, we are well aware that only in the consciousness of others we have attained to a consciousness of our own social selves with their rights and obligations. It is the activity of social control within social conduct that has built up the political individual, who maintains his own rights and recognizes those of others. He changes as that social consciousness changes. His whole political selfhood is a social endowment that comes to him from the community of which he became a part. And yet our political theory remains individualistic. Final control lies in that expression of the common social consciousness which we call public sentiment. The central fact in government is the relation of the individual to this public sentiment. The great desideratum of political reform lies in bringing this public sentiment to expression. But how inadequately is this done! How little care have we for the publicity which is the condition of the existence of the modern democratic state. On the contrary, our attention is still centered upon preserving the rights of metaphysical individuals who belong to the 18 th Century. We see that the operation of the courts in maintaining these rights frequently leads to such a travesty of social justice that the same courts are compelled to reverse their positions, as they have in the matter of the right of a laborer to make a contract-as they have in the question of contributory negligence and the fellow servant.

What is startling in these situations is that we are so committed to a fixed individualistic political theory, that we cannot adjust our practice to meet a situation that stares us in the face. We lack the scientific method that fashions new objectives to answer new problems. The laborer who in the face of starvation accepts an inadequate wage for work to be done under unhealthful conditions, is in no sense of the word the individual who enters freely into a contract, assuming rights which can be considered his own. This individual is a metaphysical entity belonging to a doctrinaire political theory. The social scientist is able to describe him as he is, handicapped economically, with no means of carrying his labor to the best market,-hungry and with a family to maintain, with instincts of workmanship, a sense of fellowship for his fellow worker, ignorant of the conditions under which he labors, of the subtle dangers to which he may be exposed, with a yearning for human response and some perception of a common good. Every one of these elements goes to determine and control his conduct in the community. No one of them does the strict political theory recognize-and there is no such interplay between social theory and social practice that we are able to give another and more adequate definition to this member of our society. Physical science has given twenty different definitions to the atom because each new one has answered to the demands of new conditions; but our courts in construing men's conduct must abide by an outworn definition because as yet the method of social practice is not scientific.

Consider a still more flagrant instance of this lack of scientific method in social control. No one who is at all conversant with the conditions under which most of our criminal class grow up, has any doubt that it is the conditions out of which these boys and girls arise plus the practice of the courts and the police that are responsible for these criminals. The earliest so-called crimes which the child commits are the expressions of the mischievous impulses of childhood. We know that children have not the knowledge nor the maturity of character which are implied in the very conception of crime. But we send them to the bars of justice. We conflict them for that which has the same moral quality as robbing an orchard or pummeling a schoolmate. We send them to an institution where they become members of the fraternity of outlaws and when they leave the jail it is with a stamp upon them that keeps most of them within the class. Society is breeding, training, and preserving most of its so-called criminal class. And we stand almost helpless before this enormity, because our theory of what constitutes a legal or illegal act, of what constitutes responsibility, of what constitutes justice is so fixed, so metaphysical, that we cannot adjust the theory to our practice. We are able to create new varieties and improve our varieties of plants and animals because we have a 
scientific method which enables us to form new ideas of what the species is, of what are the causes of defects and undesirable qualities. We can conceive of new forms and better forms because we know and can control the conditions out of which they will arise.

In the matter of justice the species are fixed by a minutely worded statute that defines the criminal and by implication the just man, and the court is occupied principally $i$ interpreting the meaning of the statute, not in determining the justice of the description. Now while it is true that the social sciences have not achieved the position of exact sciences, they can approach such situations as these with a scientific spirit, and make use of a scientific method. Indeed we see the beginnings of this change, we have already noted its somewhat tardy beginning in Education. In politics, the recall, and the referendum, imply a new mutual interplay between the individual and public sentiment, and tends to give this form of social consciousness definite organs for control in the state. In our juridical procedure the juvenile court and the system of parole find themselves quite outside the stereotyped conceptions of legal justice and recognize the relation of the misdemeanor to the conditions out of which it arose. They recognize also that justice should be a process of socializing the individual-not the awarding of fixed penalties for fixed external acts.

In a word, in the most serious problems of social practice we can see the demand for scientific method, and we can discover the beginnings of the creations of this scientific method.

This movement has many names: the conservation of human values, the insurgency, the recall and the referendum, the elimination of the juvenile delinquent, the living wage and sanitary shops, the right of the child to his childhood,-I might go on multiplying phases of the movement-but they all imply new conceptions of social objects and they all call for a right to tests of these new conceptions, these hypotheses in social practice. They all insist that no conception or definition of rights and wrongs, of individuals and states, of acts and consequences, shall be accepted and maintained unless they actually work in meeting the problems of social practice. I know of no more valuable contribution to this movement than a thoroughgoing acceptance by the community of the dictum that science has the same right of way in social practice as that which the modern world has granted it in physical practice. Since the days of the French Revolution men have been becoming more and more clearly aware that the social order changeth giving place to the new, but we have not recognized any method by which this change could e controlled. So men have clung to certain doctrines, to certain fixed ideas while they have hesitatingly surrendered others.

We need the faith of the scientist who is willing to surrender all to the test of experiment. We need to recognize further that science carries with it no fixed program. It meets each problem as it arises. The problem arises out of practice and is tested again by practice. The socialists have come forward with a fixed program. They have been quite as metaphysical as the theorists whom they have sought to supplant. But even in socialism, the programmist is giving way to the opportunist. They are beginning to demand science in social control.

Let me close with the suggestion that we are losing the meaning of life because we are not willing to conceive of social objects in terms of social practice. What all high endeavor, all devotion to humanity, what all religion has sought has been to inspire immediate conduct with the meaning of the whole of life, to gain the consciousness of the social meaning of our individual acts, and this is precisely what scientific method achieves. It states the parts in terms of the whole. It defines its objects in terms of the processes that are going on. Science in social practice must be profoundly religious. 